\title{
The Research of Social Network Analysis on College Students' Interactive Relations
}

\author{
Chang Chen, Wuhan University, Wuhan, China \\ Min Chen, Wuhan University, Wuhan, China
}

\begin{abstract}
Nowadays the number of college students' suicides are increasing for the insufficient social support or poor interpersonal relations. Furthermore, not much attention has been concerned to students' interpersonal relations when handling student affairs and only very limited information about students' interaction network is available. This paper studies the peer network of college students by using the tool of social network analysis. And it aims to serve as instrumental support for students to foster and develop harmonious interpersonal relations. It offers new information for school counsellor to better handle student affairs and provides information support for the carrying out of moral and ideological guidance for students.
\end{abstract}

\section{KEYWORDS}

College Suicide, Harmonious Interpersonal Relation, Interpersonal Relations, Quantitative Description, Social Network Analysis, Social Support, Student Affairs, Students' Interactive Relations

\section{INTRODUCTION}

In recent years, more and more researches such as Bright, et. al. (2012); Cho, et. al. (2007); DeJorge-Moreno, (2012) use the method of social network analysis (hereinafter referred to SNA) to study problems relating to college students' interpersonal relations and social network. SNA is an important branch of the western sociology. Formulated during 1930s and 1940s, it is a frequently referred paradigm and perspective for studying interpersonal relations and its structure. It settles many binary problems with an emphasis on relational data rather than attribute data by De-Marcos L, et. al. (2014); Janssen J, et al. (2012); Kitsak M, et al. (2010); Miranda, (2006); Radil, et. al. (2010); Reid, et. al. (2007); Sen, et. al. (2016). SNA comprises of individual network analysis and holistic network analysis (Peng S et al. (2017, 2018); Riquelme F et .al (2018); Tao, et. al. (2006); Van der Hulst, (2009)). Holistic network analysis, as a brand-new research paradigm, brings breakthrough to the development of social network statistical technologies and is of great significance to the holistic study of groups. The holistic network can be used to study the overall relationship of all network members and describe the social support structure as a whole, so as to enable the clarification of the interaction pattern and fractions within the group, which may further explain the behavior model of the group and establish a social network model with census and review followed.

University and college campuses are semi-closed space, where students' social interaction is rather simple, mainly with teachers and classmates. Their interactions with teachers are focused on study while their peer relations with classmates are the main source of social communications. Increasing depression and suicide cases resulting from low social support represent the malfunction of college students' interpersonal relationships. Friends are, in many cases, their main source of social 
support as well as the major form of social interactions. Studying college students' friends network with the SNA method will provide instrumental support for the establishment and development of harmonious interpersonal relations. The Theory of Relations Management evolved from the Social Network theory can also serve as a valuable reference for establishing management institutions that take one class as the basic management unit.

\section{EXPERIMENT DESIGN}

\section{Research Content}

In the context of interpersonal interactions, social network is usually divided into three types, i.e. friendship network, information network and consultancy network. This paper studies universities and college students on their interpersonal network from the perspective of emotional support. Emotional support refers to students' interactive experience during their study and life, including some intimate emotional actions and emotionally supportive utterances such as "participate in activities together", "eat together", "chat and communicate" and so on.

In conclusion, the research content of this paper includes: (1) the basic situation of the interpersonal relationships formed through the emotional support network of students from the Excellence Class majoring in software engineering; (2) the mutual influence of interpersonal relationships and academic performance; (3) the similarities and differences of interpersonal relationship networks of girls and boys.

\section{Participants}

The participants of this research are students from Excellence Class One of the software engineering major of some university. The Excellent Class is a strategy proposed by Chinese Ministry of Education to train excellent engineers in colleges. Members of Excellent Class are selected from ordinary classes through some examinations. There are in total 30 students, nine of whom are girls and the other 21 are boys. The average GPA of the whole class is 3.3514 while that of girls is 3.420088 , slightly higher than the class average. And the total GPA of girls is also higher than boys'.

\section{Data Collecting and Processing}

This research collects data through questionnaires and "informants". The questionnaires, with 100\% response rate, is the main source of data. Under the principles of technicality and confidentiality, the questionnaires were completed after the class counselors communicate with participants separately. And because the participants were quite cooperative, the data has relatively high reliability. Later, "informants" inquired about details of the classes studied and revised some questionable data after revisiting the corresponding respondents. The "informants" are students who collect information secretly for us in the class. To ensure the validity of the research, stipulations have been applied to some data. 29 of the total 30 students in the class have answered the following questions:

For items "Chat and communicate" and "Eat together", if two respondents both choose "Occasionally" or "Always" for each other, then value of " 1 " is added to their corresponding element position in the matrix, otherwise "0". For the item "Participate in activities together", if two participants tick the same choice (e.g., Self-study; Exercise; Students' associations) for each other, then value of " 1 " is added to their respective element position in the matrix, otherwise " 0 ". For the students in colleges the most common thing is studying together in the classrooms. So we consider it could be an index for "participate in activity together" (see Table 1). 
Table 1. Questionnaire items

\begin{tabular}{|l|l|}
\hline Question & Answer scope \\
\hline $\begin{array}{l}\text { Chat and communicate } \\
\text { frequency }\end{array}$ & $\begin{array}{l}\text { Always->2; Occasionally- }>1 ; \\
\text { Never- }>0\end{array}$ \\
\hline Eat together frequency & $\begin{array}{l}\text { Always->2; Occasionally- }>1 ; \\
\text { Never- }>0\end{array}$ \\
\hline Participate in activities together frequency & $\begin{array}{l}\text { Self-study- }>1 ; \\
\text { Exercise- }>2 ; \\
\text { Students' associations- }>3 ; \\
\text { Never- }>0\end{array}$ \\
\hline Ranking of friend closeness & $\begin{array}{l}\text { Intimate- }>1 \\
\text { Remote- }>29\end{array}$ \\
\hline
\end{tabular}

\section{Research Methodology}

This paper studies the class's the holistic interpersonal relationships using the method of Whole Network Analysis of SNA. The major SNA indicators employed include network density, centrality, matrix correlation and so on. And the instruments used are socigram and SNA.

\section{Sociogram}

There are two kinds of formal manifestations of social network: sociogram and matrix algebra. Sociogram can describe relationship networks in a way that is concise and clear with relations between each network node and features of the network structure explicit at first glance. This paper will demonstrate the structural features of the interpersonal network in different classes with the help of sociogram.

\section{Network Density}

Density is the quantitative demonstration of the overall distribution of interpersonal relationships in the social network, reflecting the degree of closeness between community members. It can be formulated as following:

$$
\mathrm{D}=\frac{\sum_{\mathrm{i}=1}^{\mathrm{N}} \sum_{\mathrm{j}=1}^{\mathrm{N}} \mathrm{Z}_{\mathrm{ij}}}{\mathrm{N}^{2}-\mathrm{j}}
$$

In the equation there are $\mathrm{N}$ nodes in the oriented network, the value of $\mathrm{Zij}$ is 1 if there is an edge comes from node i to node $\mathrm{j}$, otherwise it's 0 .

The more interactions between members of a group at a certain scale, the greater the density of the network. Through this indicator, we can observe the interaction frequency of interpersonal network in different classes.

\section{Centrality}

Centrality analysis is the most commonly used method to evaluate the importance of each actor in the overall network. There are mainly two indicators for centrality: central degree and central potential. The central degree of individuals measures the location of an individual or a node in the network center, which suggests its importance in the network. The following equation shows the value of central degree: 
If there are total gij paths between node $\mathrm{i}$ and $\mathrm{j}$, furthermore there are gij(k) paths showing node I can reach node $\mathrm{j}$ through node $\mathrm{k}$; then we can use bij(k) to describe the ability of node $\mathrm{k}$ to control the communications between node I and $\mathrm{j}$. The value of bij $(\mathrm{k})$ is

$$
b_{i j}(k)=\frac{g_{i j}(k)}{g_{i j}}
$$

Indeed bij(k) means the possibility of crossing node $\mathrm{k}$ when node $\mathrm{i}$ want to reach node $\mathrm{j}$. So when we want to calculate the central degree of node $\mathrm{k}$, all the possibilities of crossing $\mathrm{k}$ between any node pairs in the network should be summed up. It can be showed as following:

$$
\mathrm{C}_{\mathrm{c}(\mathrm{k})}=\sum_{\mathrm{i}}^{\mathrm{N}} \sum_{\mathrm{j}}^{\mathrm{N}} \mathrm{b}_{\mathrm{ij}}(\mathrm{k}), \text { jant to rea }<\mathrm{j}
$$

And central potential refers to the trend of the whole network converging to an individual. It is used to descript the whole network centrality. So we firstly should find the node with maximum central degree, then calculate the central degree difference between this node and any other nodes. Then we sum up all the difference and use the sum to divide the maximum value of the difference. It can be formulated as following:

$$
\mathrm{C}=\frac{\sum_{\mathrm{k}=1}^{\mathrm{N}} \mathrm{C}_{\mathrm{cmax}}-\mathrm{C}_{\mathrm{c}(\mathrm{k})}}{\max \left[\sum_{\mathrm{k}=1}^{\mathrm{N}}\left(\mathrm{C}_{\mathrm{cmax}}-\mathrm{C}_{\mathrm{c}(\mathrm{k})}\right)\right]}
$$

This paper chooses degree centrality as the major indicator of centrality analysis. An individual with high degree centrality means he/she has connections with many other actors in the network and thus is more influential. Average degree centrality is the average value of all degree centrality.

\section{DATA ANALYSIS}

\section{Encoding of Participants}

In order to protect the participants' privacy while also visualizing the data analysis, the author encodes each participant with a three-digit number. The hundreds digit represents gender of the participant ("1" for boys and "2" for girl), and the combination of the tens digit and the units' digit refers to the sequence of the participant. For example, 121 means the No.21 boy and 209 means the No. 09 girl.

\section{Analysis of the Interpersonal Network Structure}

\section{Analysis Based on Multi-Dimensional Scale (MDS)}

MDS can be used to vividly illustrate actors' relationship network and analyze the encoded data so as to describe the distance between actors in the multi-dimensional map. By analysing the "Closeness Matrix" with MDS, the distance map of this class in a two-dimensional space is drawn in Figure 1. The "Closeness Matrix" is a matrix whose element values are used to manifest the closeness of relative peoples. If two actors are closer from each other, it means the they communicate more frequently. 


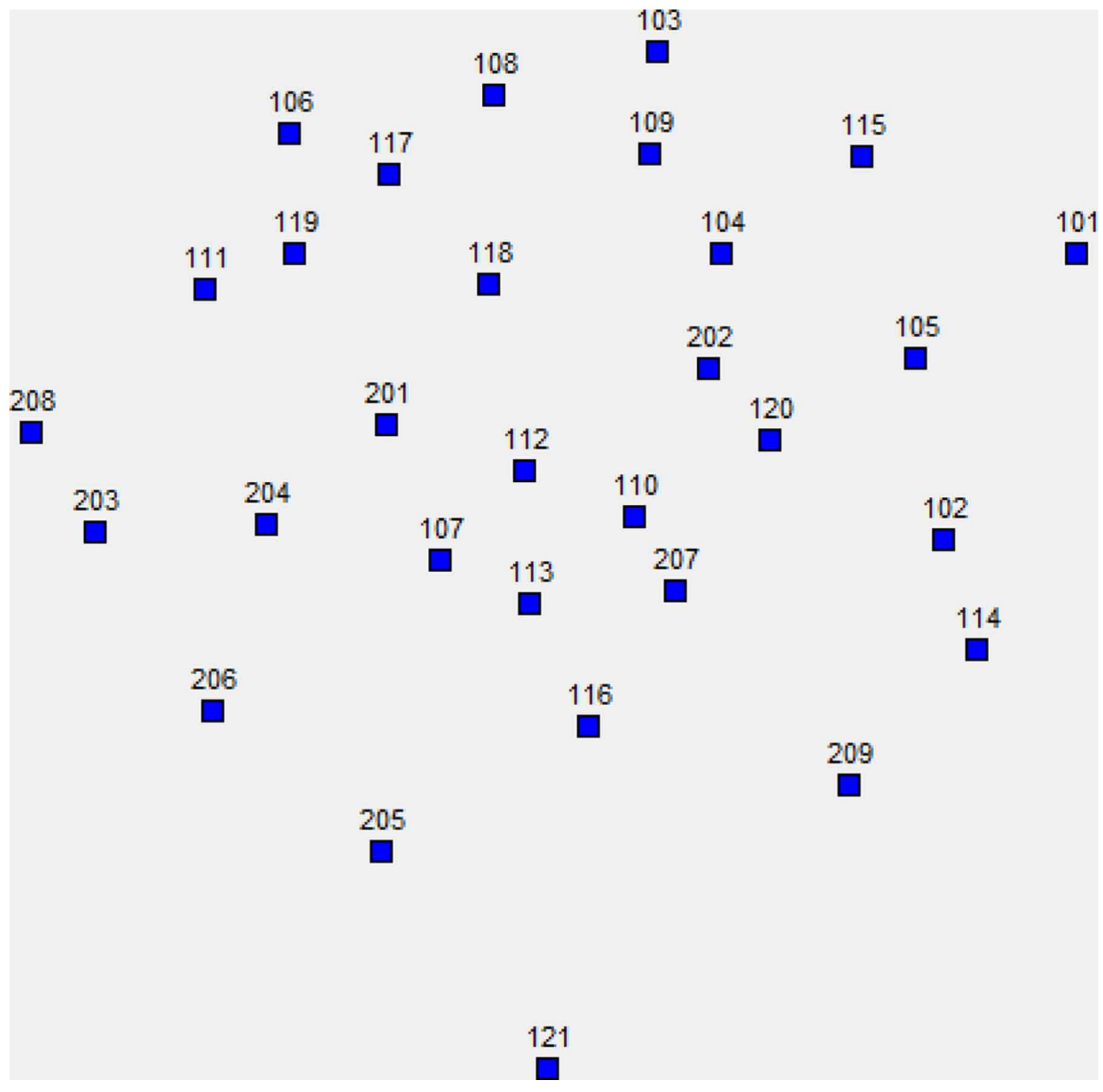

The analytical tool used in this paper is Ucinet, a software invented mainly for the purpose of network analysis by a group of network analysts from the University of California, Irvine(Borgatti, et. al. (2002)). Deviation is inevitable when using MDS to present students' relationship network, but the outcome can basically reflect the situation of interactions in this class. It is clearly shown that mutual distance between boys is shorter than girls, indicating that relationships between boys are closer. And according to information from the "informants", Boy 121 hasn't really fit in because he just transferred from another school. Besides, but interactions between other boys in the class is more frequent than that between girls, which also further prove the accuracy of MDS.

\section{Analysis of Characteristics of Boys' and Girls' Way of Making Friends}

It is apparently shown in the Communication Matrix as Figure 2 that the frequency of social interactions between boys is the highest, following by the interactions between boys and girls and the social interactions among girls is the least frequent. Just as Douvana and Adelson (1996) emphasized: "Youngsters do not take the initiative to screen friendships, but are often negatively driven into 


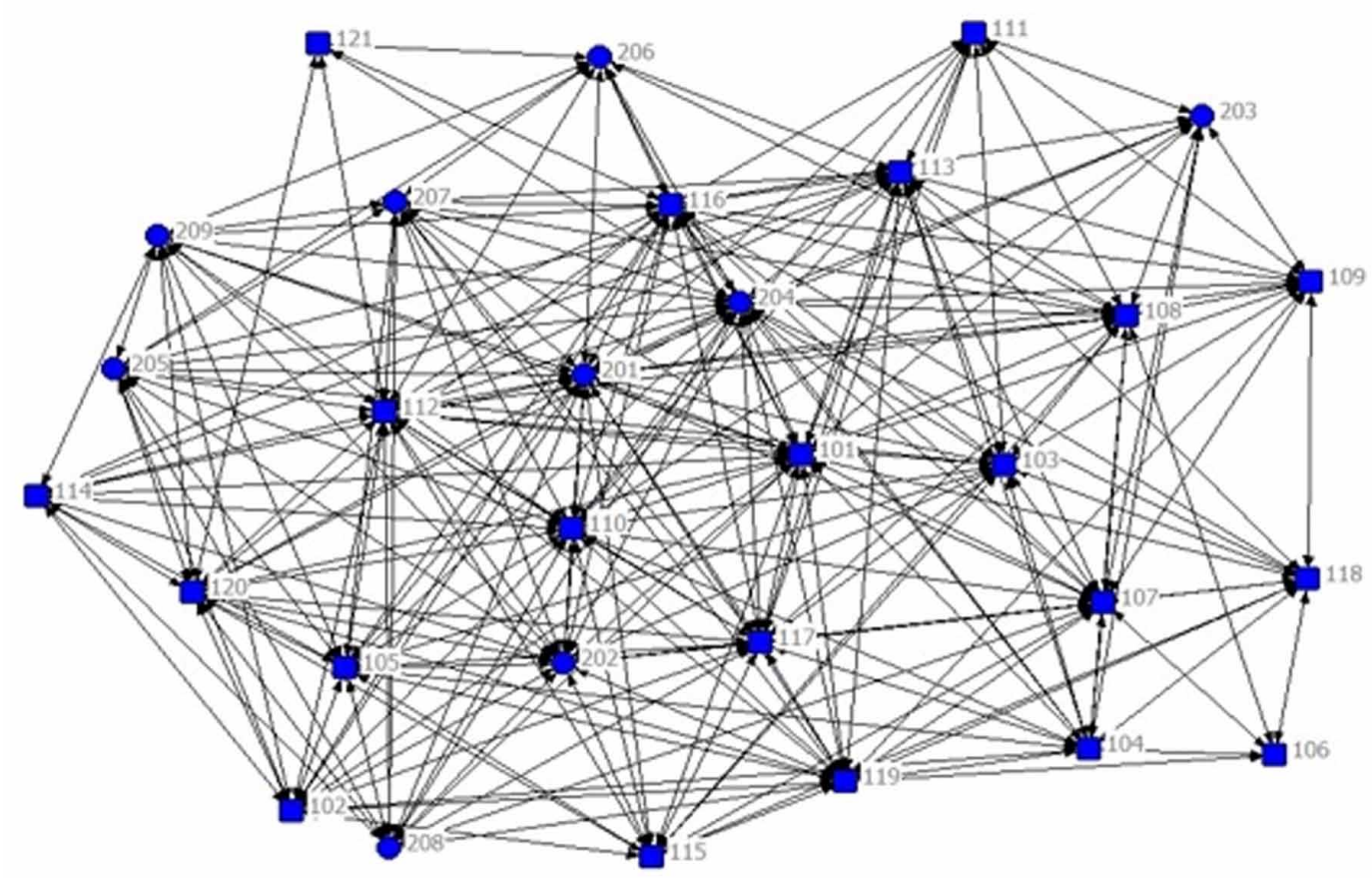

the network of friendships. They begin to develop friendships unconsciously with the preliminary structure prepared by the society".

Two reasons explain the different friendship engagement models of boys and girls. Firstly, it is because boys and girls use different ways to establish close friendships. Girls' closeness with friends is cultivated through chatting while boys establish theirs through common activity engagement. Secondly, it is because that in the traditional Chinese culture context, men are born with the responsibility of starting a family and achieving career success so as to widely gain fame, therefore they need extensively social interactions to achieve those missions. And "the degree of social interactions" becomes an important indicator of a man's success as well as an important standard for men's self-identification. Consequently, boys are more likely to initiate friendship proactively while girls only interact with fixed friends, among whom roommates are more likely to become their intimate friends.

\section{Quantitative Analysis of Centrality}

This part only analyses the interaction between core members in the class. The number of lines, which is generated according to the times in which two respondents choose each other as the one to interact with, represents the interaction frequency between the two participants.

As shown in Figure 3, Boy No. 10 (110) and Girl No.7 (207) are both in the core position of the "Good Friends Matrix" and have high in-degree and betweenness. High in-degree means many classmates choose them to be good friends and high betweenness means they own substantial friendsource in this network. By analyzing the degree centrality of the "Good Friends Matrix" without previous symmetrical processing, the author draws the top five in terms of in-degree: 110hey own substantialsubstantialss means thehe class monitor and 207 the class treasurer and psychological commissioner with the highest GPA in the class. And 113, 112, 107 have good academic performances 


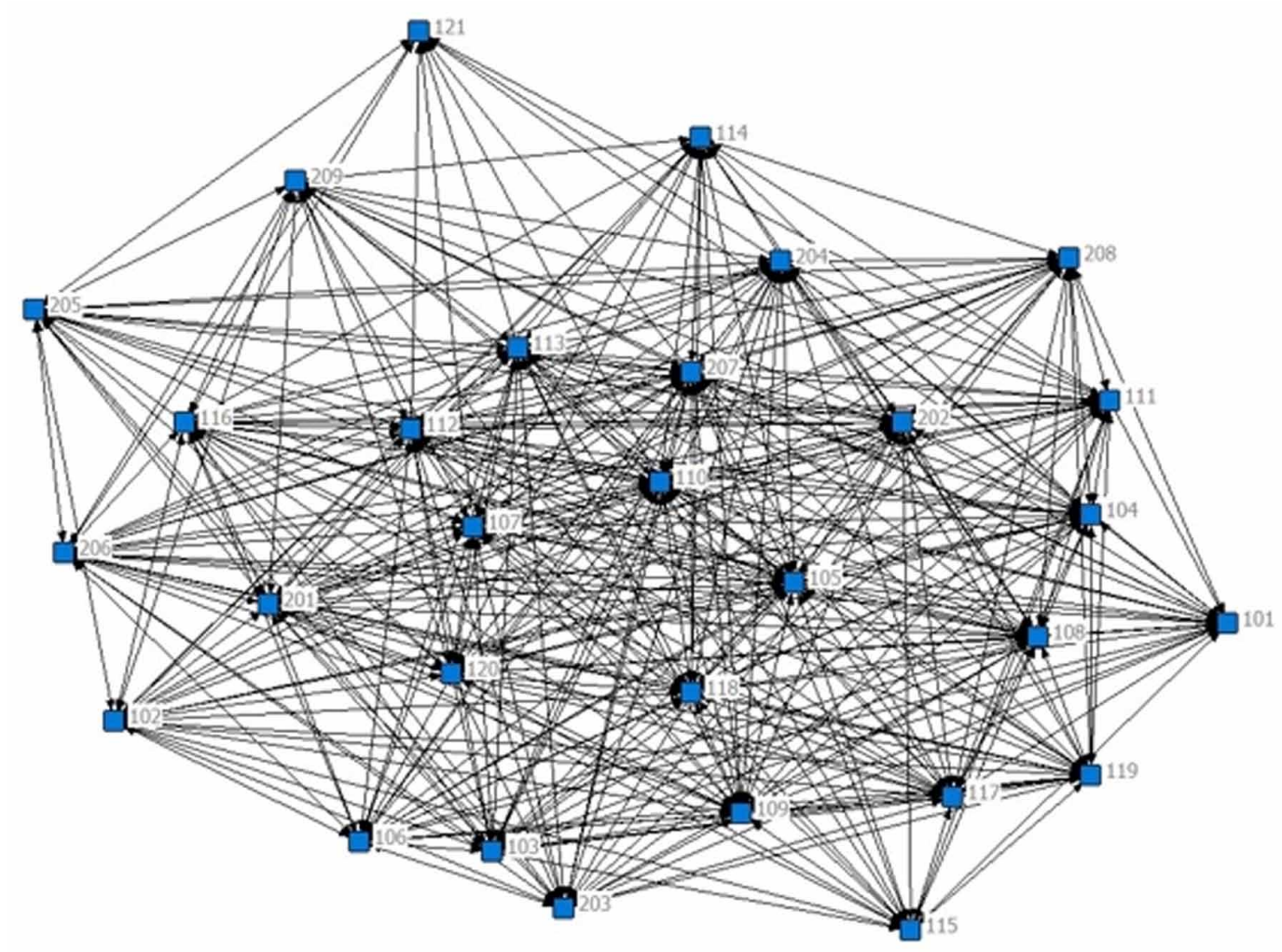

and their GPAs are all above the class average. Actors with high betweenness means they own substantial friend-source in this network.

According to Burt's "Structural Holes" theory, members with high betweenness hold more information flows and all kinds of opportunities. This could enable them to control other group of people and gain intermediary profits. "Structural hole" refers to the gap in social network, that is, one or some individuals in social network have direct contact with some individuals and have no direct contact with other individuals. So there is no direct connection or disconnection. From the perspective of the whole network, it seems that there is a hole in the network structure. Within a class, students with high betweenness are of great significance in resolving group contradictions. According to the counselor, the class committee are selected by election with each candidate's qualities taken into consideration. Consequently, it can be said that the class committee members are individuals with high in-degree and betweenness. At the beginning of the term, they all have similar centrality. However, as the monitor's function becomes more prominent daily practice, he gradually becomes the "hub" of the class with other members' core position weakened.

\section{Analysis of the "Disliked Cohort"}

The "disliked cohort" refers to those who are marginalized in a group, which generally falls into the following categories:

1. Individuals with lower grades among friends. Individuals are graded according to the amount of their network resources, and those with lower grades are the ones with fewer resources. In this case, for example, 121, 115 and 114 are individuals with lower grades in terms of betweenness. 
2. The individual who is remotest related with the class. In the "Good Friends Matrix", Boy No.21 (121) has the lowest interaction frequency with the class and limited connection points, which suggests that 121 is a person who neither recognize other classmates or is accepted by others and has the tendency to seclusion. So the counselor should pay timely attention to him.

3. Outliers in the "Good Friends Matrix". As shown the matrix, there are four outliers among girls, i.e. 205, 206, 208, 209. According to the "informants", three of them are from the same dormitory. Therefore, it can be deduced that students in this dorm are remotely connected with other classmates and they seldom participate in group activities. A leader is in need to liven them up. To properly deal with this, the counselor may have some outgoing student transferred into this dorm so as play the role as a catalyze or even "assimilate" them.

\section{INSPIRATION}

\section{The Impact of Peer Friendships on Academic Performance}

Peer friendships with classmates plays an important role in the interpersonal network of university and college students. And it has both positive and negative impacts. This research conducts a quantitative elaboration on the impact of peer friendship on students' GPAs. The average GPA of the class surveyed is 3.35 and students whose GPA is above the average, except two marginalized individuals (209 and 206), are all at the core position of the interpersonal network and have close interactions with their classmates. Two conclusions can be drawn from those data. Firstly, students are more willing to interact with classmates with a higher GPA. Secondly, students with a higher GPA get along better with classmates. It can be fairly said that students with closer peer friendships with their classmates and a higher GPA are more likely to be accepted by the group.

\section{The Application of the Theory of Interpersonal Relations Management in Handling Student Affairs}

The theory of interpersonal relations management is evolved from SNA, with an emphasis on study of different relationship patterns and the network structure of those ties. It lays stress on managing actors from the perspective of interpersonal relationships and has been sufficiently developed in the field of business management. Consequently, it is of practical significance to introduce this theory into school management, especially to students management. Based on the research outcome, the author would like to make the following observations:

Members of the class committee should be selected based on their higher centrality and betweenness with personal qualities taken into consideration. Because those individuals have strong connections and their influence and informal power would deliver important effect on other students' actions. And therefore they may play up their functions in handling crisis, contractions or in mobilizing students.

Students should be consciously guided in establishing and modifying their interpersonal relationship structure. It is found in this research that girls in the class are more likely to show passive social motivation and to subscribe to the space restrictions and thus limit the daily interactions within their dorms. Always interacting with fixed companions is not beneficial for girls' further development, therefore they should enlarge their interaction networks. Confining the interaction scope to only the core peer group will lead to limited social capital with high homogeneity. This also explains why successful females are always rare since ancient times. Consciously guiding students to establish and modify their interpersonal relationship structure will greatly benefit them in personal development.

Class counselor and mentor should pay more attention to the disliked cohort. Disliked students in the friendship network are always outliers or marginalized individuals with little popularity among classmates. Class counselor and mentor should give more attention to them. The disliked cohort has lower social support from their peer group and thus is not accessible to timely aid when 
contradictions occur between the environment and themselves. Besides, low level of social support is always closely related with a high occurrence rate of depression, which may in return further interrupt the establishment of peer friendships. Those cohorts might consequently be trapped in a vicious cycle and the depression situation can be aggravated if things persist on for a long time. Without proper settlement of mental health problems, individuals are very likely to behave irresponsibly for themselves, seriously affecting the social harmony. Insufficient social support is to blame for the increasing cases of university and college students committing suicide and suffering depression. Therefore, from the perspective of management, the behaviors and mental dynamics of disliked cohort are in need of special attention. More guidance and instructions should be given to them. The guidance and instructions are conducted by class counselor or mentor which include taking to them, sending them to see psychiatrists or arrange meeting between them and their friends et al. Specifically, more opportunities for social interactions and sharing class responsibilities should be provided to the disliked cohort.

\section{Common Interests May Efficiently Increase the Closeness Among Friends}

Data from the choice "participate in activities together" shows that friends with higher closeness tend to participate in activities together, especially in sports activities and students' associations. Therefore, to maintain a good relationship, students can start from participating in activities that they are commonly interested in. Well-developed friendships and partnerships are helpful for students' academic progress and personal growth, bringing them more harmonious interpersonal relationship and more social support.

\section{CONCLUSION}

It is beneficial for handling students' affairs to timely learn about students' friends network as well as their behavior models. Sound peer relations among students will help strengthen the class solidarity while fixed fractions will hamper class managements. In order to enhance class solidarity, fraction confinement should be broken down in group activities so as to enable students who are remotely related to merge into the class and get opportunities to interact with others.

SNA provides a feasible method to quantitatively describe students' interactive relations. This paper only represents an individual case study whose conclusion provides some new observations to social interpersonal relations study regardless of a relatively small number of samples. Follow-up study would see the following improvement:

1. A larger number of samples. Comparative study will be carried out among different classes on their social network relations.

2. More comprehensive data of participants' network relations. Diagrams of network structure will be drawn chronologically for showing the dynamics of network interpersonal relations structure.

\section{REFERENCES}

Borgatti, S. P., Everett, M. G., \& Freeman, L. C. (2002). UCINET 6 for windows. Analytic Technologies.

Bright, D. A., Hughes, C. E., \& Chalmers, J. (2012). Illuminating dark networks: A social network analysis of an Australian drug trafficking syndicate. Crime, Law, and Social Change, 57(2), 151-176. doi:10.1007/ s10611-011-9336-z

Cho, H., Gay, G., Davidson, B., \& Ingraffea, A. (2007). Social networks, communication styles, and learning performance in a CSCL community. Computers \& Education, 49(2), 309-329. doi:10.1016/j.compedu.2005.07.003 
De-Jorge-Moreno, J. (2012). Using social network and dropbox in blended learning: An application to university education. Business. Management in Education, 10(1), 221-232.

De-Marcos, L., Domínguez, A., Saenz-de-Navarrete, J., \& Pagés, C. (2014). An empirical study comparing gamification and social networking on e-learning. Computers \& Education, 75, 82-91. doi:10.1016/j. compedu.2014.01.012

Douvan, E. A., \& Adelson, J. (1966). The Adolescent Experience. Academic Press.

Janssen, J., Hurshman, M., \& Kalyaniwalla, N. (2012). Model selection for social networks using graphlets. Internet Mathematics, 8(4), 338-363. doi:10.1080/15427951.2012.671149

Kitsak, M., Gallos, L. K., Havlin, S., Liljeros, F., Muchnik, L., Stanley, H. E., \& Makse, H. A. (2010). Identification of influential spreaders in complex networks. Nature Physics, 6(11), 888-893. doi:10.1038/nphys 1746

Lubbers, M. J., Van Der Werf, M. P. C., Snijders, T. A. B., Creemers, B. P. M., \& Kuyper, H. (2006). The impact of peer relations on academic progress in junior high. Journal of School Psychology, 44(6), 72-78. doi:10.1016/j. jsp.2006.07.005

Peng, S., Wang, G., \& Xie, D. (2017). Social influence analysis in social networking big data: Opportunities and challenges. IEEE Network, 31(1), 11-17. doi:10.1109/MNET.2016.1500104NM

Peng, S., Zhou, Y., Cao, L., Yu, S., Niu, J., \& Jia, W. (2018). Influence analysis in social networks: A survey. Journal of Network and Computer Applications, 106, 17-32. doi:10.1016/j.jnca.2018.01.005

Radil, S. M., Flint, C., \& Tita, G. E. (2010). Spatializing Social Networks: Using Social Network Analysis to Investigate Geographies of Gang Rivalry, Territoriality, and Violence in Los Angeles. Annals of the Association of American Geographers, 100(2), 307-326. doi:10.1080/00045600903550428

Reid, E., Chen, H., \& Xu, J. (2007). Social network analysis for terrorism research. In H. Chen (Eds.), Handbook in information systems: National security (pp. 243-270). Academic Press.

Riquelme, F., Gonzalez-Cantergiani, P., Molinero, X., \& Serna, M. (2018). Centrality measure in social networks based on linear threshold model. Knowledge-Based Systems, 140, 92-102. doi:10.1016/j.knosys.2017.10.029

Sen, F., Wigand, R., Agarwal, N., Tokdemir, S., \& Kasprzyk, R. (2016). Focal structures analysis: Identifying influential sets of individuals in a social network. Social Network Analysis and Mining, 6(1), 17. doi:10.1007/ s13278-016-0319-z

Tao, Y., Wei, Q., Xu, Z., Bai, R., Li, Y., Luo, C., Dong, Y., Gao, G., \& Lu, Y. (2006). Holistic and network analysis of meningioma pathogenesis and malignancy. BioFactors (Oxford, England), 28(3-4), 203-219. doi:10.1002/ biof.5520280307 PMID:17473381

Van der Hulst, R. C. (2009). Introduction to Social Network Analysis (SNA) as an investigative tool. Trends in Organized Crime, 12(2), 101-121. doi:10.1007/s12117-008-9057-6 
Chen Chang received the master degree in service science in 2009 from Wuhan University, He is now the Director of administration office, School of computer science, Wuhan University. His research interests include service science and computer network.

Chen Min received the Ph.D degree in remote sense in 1998 from Wuhan University, He is now a professor of School of computer science, Wuhan University. His research interests include service science and computer network. 